\title{
Higiene Pública e normatização social na Corumbá Imperial ${ }^{1}$
}

\section{Public Hygiene and social standardization in Corumbá Imperial}

\author{
Fabiano Quadros Rückert* \\ https://orcid.org/0000-0002-3023-1120 \\ Divino Marcos de Sena* \\ https://orcid.org/0000-0002-3023-1120
}

\begin{abstract}
Resumo
0 artigo aborda a atuação do poder público no processo de normatização do espaço urbano ocorrido na cidade portuária de Corumbá (Brasil) nas décadas finais do Império. Contempla questões referentes à higiene pública e à salubridade urbana a partir de fontes documentais produzidas pela municipalidade de Corumbá no contexto de inserção da cidade nas rotas do comércio internacional. A Introdução do artigo apresenta informações sobre as mudanças econômicas, sociais e institucionais ocorridas na cidade após a reabertura da navegação no rio Paraguai. A primeira seção trata das relações entre as Posturas Municipais e a higiene pública. A segunda aborda o distanciamento entre as leis que tratavam da higiene pública e as práticas sociais em vigor. A seção final do texto apresenta as reações da sociedade corumbaense e do poder público diante da epidemia de Cólera que atingiu a cidade no biênio 1886/1887.
\end{abstract}

Palavras chaves: Higiene Pública, Corumbá, Brasil Imperial, Posturas Municipais.

\begin{abstract}
The article addresses the role of the public power in the process of standardization of urban space that occurred in the port city of Corumbá (Brazil) in the final decades of the Empire. It addresses issues related to public hygiene and urban health from documentary sources produced by the municipality of Corumbá in the context of the insertion of the city in international trade routes. The Introduction of the article presents information on the economic, social and institutional changes that occurred in the city after the reopening of navigation on the Paraguay river. The first section deals

\footnotetext{
${ }^{1}$ A produção deste artigo contou com o apoio da Fundação Universidade Federal de Mato Grosso do Sul. *Doutor em História. Professor Adjunto na Universidade Federal de Mato Grosso do Sul - Campus do Pantanal. E-mail: fabianoqr@yahoo.com.br

${ }^{* *}$ Doutor em História. Professor Adjunto na Universidade Federal de Mato Grosso do Sul - Campus do Pantanal. E-mail: divinosena@yahoo.com.br
} 
with the relationship between Municipalities and public hygiene. The second deals with the distance between the laws that dealt with public hygiene and the current social practices. The final section of the text presents the reactions of the corumbaense society and the public power to the cholera epidemic that hit the city in the 1886/1887 biennium.

Keywords: Public Hygiene, Corumbá, Imperial Brazil, Municipal Postures.

\section{Introdução}

Localizada no extremo da fronteira Oeste do Brasil com a Bolívia, à margem direita do rio Paraguai, em pleno Pantanal Sul-Mato-Grossense, a cidade de Corumbá é a sede de um dos municípios brasileiros com maior extensão territorial. Nas suas origens, a criação e o desenvolvimento do espaço urbano de Corumbá mantém afinada relação com as disputas que ocorreram entre os países platinos que conquistaram suas independências ao longo da primeira metade do século XIX, especialmente a República do Paraguai e o Império Brasileiro, e com a presença da navegação a vapor no interior do Brasil.

Integrada à então província de Mato Grosso, Corumbá fazia parte de um vasto território reivindicado pelo governo paraguaio durante a Guerra entre este país e a Tríplice Aliança (1864-1870). Portanto, situada em área litigiosa, Corumbá foi ocupada pelas tropas de Solano Lopez em princípio de 1865, quando autoridades imperiais e moradores brasileiros fugiram dos ataques paraguaios para outras regiões de Mato Grosso e da fronteira com a Bolívia.

A ocupação paraguaia bloqueou o ingresso de embarcações brasileiras que navegavam no rio Paraguai, via estuário do Prata, desde a segunda metade da década de 1850. Essa primeira etapa da navegação a vapor provocou transformações econômicas e sociais em Mato Grosso, especialmente na sua porção sul e na fronteira com a Bolívia. Corumbá foi beneficiada como um porto internacionalizado, recebendo pessoas de diferentes procedências, ganhou ares de espaço urbano e já era apontada como o entreposto comercial da província.

Com o bloqueio e a ocupação paraguaia tais transformações foram interrompidas e retomadas com maior fôlego a partir do término do conflito e da vitória da Tríplice Aliança (Brasil, Argentina e Uruguai). Corumbá retornou aos domínios do Império e passou a conviver com um processo de 
(re)organização a partir de iniciativas estatais e de particulares. Com a reabertura da navegação às embarcações brasileiras e estrangeiras, ela recebeu antigos e novos moradores, investimentos, isenções ficais por alguns anos das mercadorias que seriam importadas pela província e as exportações dos gêneros de produção nacional, presença de atividades e instalação de casas comerciais, além de instituições responsáveis em fazer os efeitos da Guerra serem eliminados com as novas possibilidades que a delimitação de fronteiras territoriais, os acordos de paz e a navegação trouxeram para aquela parte do interior do Brasil (SENA, 2017).

A reabertura da navegação no rio Paraguai possibilitou um contato mais rápido com a região platina e com portos brasileiros. Corumbá, gradativamente, se destacou como um empório comercial internacionalizado em Mato Groso, em contato com a Bolívia, integrado à área platina e conectado ao mercado mundial.

Cabe destacar que tais transformações estiveram articuladas com a dinâmica do capitalismo, com a mundialização da economia. Países, como o Brasil, receberam o entusiasmo do comércio livre internacional vivenciado na Europa, do qual a estrada de ferro e o barco a vapor traduziram a possibilidade de transportar maior volume de mercadorias e pessoas, e eram vistos como os mais eficazes e modernos meios de transporte existentes (HOBSBAWM, 1982).

A população de Corumbá igualmente aumentou. Nas últimas décadas do oitocentos, de 3.361 pessoas em 1872 (DIRETORIA GERAL DE ESTATÍSTICA, 1874), ela passou para 8.414 em 1890 (DIRETORIA GERAL DE ESTATÍSTICA, 1898). A pluralidade da população, composta por mulheres e homens brancos, nacionais e estrangeiros, pretos (livres e escravos), indígenas e mestiços (livres e escravos) não destoava do cenário mato-grossense como um todo. ${ }^{2}$

Paulatinamente, o espaço urbano passou a ser um centro governamental, político e comercial, com concentração e distribuição de mercadorias e cargas, prestação de variados serviços, de comunicação, de relações etc. Um aparato administrativo, judicial e fazendário foi criado em Corumbá. A (re) organização do seu território fez parte da redefinição da área provincial naquele momento, com criação de municípios, freguesias, distritos, comarcas, nomeação de autoridades, eleições, divisão de competências etc. Tais medidas resultaram de interesses do Estado em pretender organizar, controlar e administrar o território e as suas populações que tinham recém-saído do domínio estrangeiro e estavam situadas em área de fronteira geopolítica (SENA, 2017).

${ }^{2}$ Sobre a sociedade mato-grossense do período imperial ver: PERARO, 2001; e SENA, 2013. 
Nos decênios finais do Império, várias instituições militares e públicas fizeram-se presentes em Corumbá, entre quais, destacamos: Exército, Marinha e Guarda Nacional, Alfândega, Câmara Municipal, Delegacia e Subdelegacias de Polícia, Coletoria Provincial, Correios, Consulados (do Paraguai, Bolívia, Argentina, da República Oriental do Uruguai, de Portugal e da Itália), Juizados (Municipal e de Direito), entre outras. Uma das medidas essenciais para a governança foi a restauração do território municipal e a efetiva instalação da municipalidade. Corumbá foi elevada à categoria de vila em 1862, anterior à guerra, mas diante de entraves (administrativo, pessoal e orçamentário) não foi efetivada a instalação do seu governo municipal. Somente em 1872, foram realizadas as primeiras eleições para juízes de paz e vereadores e a instalação da Câmara Municipal (SENA, 2017).

A presença de municipalidades no Brasil esteve ligada, desde os tempos coloniais, à elevação de um povoado à categoria de vila e a consequente independência administrativa do "termo" ou território municipal (BICALHO, 2003). No Brasil independente as câmaras continuaram responsáveis pelo governo econômico e municipal das vilas e cidades já existentes e naquelas que fossem criadas. A Constituição de 1824 conferiu às câmaras somente atribuições administrativas e as subordinou política e administrativamente às instâncias provinciais. Posteriormente, em 1828, o Regulamento das Câmaras Municipais do Império definiu os critérios para composição e funcionamento das câmaras e fixou de forma detalhada as responsabilidades e competências das municipalidades (Leis e Decretos do Império. 1828).

No decorrer do período imperial, sobretudo com o Ato Adicional de 1840, as câmaras perderam uma parte das suas competências na gerência municipal (CAMPOS, 2004). Contudo, apesar disto, elas guardavam ampla influência em seu campo de atuação, especialmente quando os assuntos se referiam à organização e ordenamento do perímetro urbano.

Na sequência do texto, vamos abordar o trabalho da Câmara Municipal de Corumbá na promoção da higiene pública e da salubridade urbana na Corumbá Imperial. Mas antes de avançar para esta abordagem, importa informarmos ao leitor que os documentos consultados procedem principalmente do acervo documental da Câmara Municipal de Corumbá. Neste acervo, localizamos Relatórios de Fiscais da Câmara, Ofícios do Delegado de Higiene do Município, Ofícios do Delegado de Saúde do Porto e Relatórios e ofícios do Presidente da Câmara abordando as iniciativas da municipalidade no contexto 
da epidemia de Cólera de 1886. Utilizamos também dois Códigos de Posturas de Corumbá localizados no Arquivo Público do Estado de Mato Grosso.

\section{As Posturas Municipais em Corumbá e a busca da salubridade urbana}

O Regulamento das Câmaras Municipais do Império, promulgado em 1828, constituiu-se no principal marco jurídico para a atuação política das Câmaras de Vereadores. Consta, no artigo 71 do Regulamento, que:

As Câmaras deliberarão em geral sobre os meios de promover e manter a tranquilidade, segurança, saúde e comodidade dos habitantes; o asseio, segurança, elegância e regularidade externa dos edifícios e ruas das povoações e, sobre estes objetos, formarão as suas posturas, que serão publicadas por editais, antes e depois de confirmadas (Leis e Decretos do Império. 1828. L042, p. 192-196v).

Atendendo ao Regulamento de 1828 , no momento inicial de sua instalação, a edilidade de Corumbá foi orientada pela presidência da província a elaborar suas Posturas, para, a partir delas, organizar a administração do novo município. As Posturas Municipais correspondiam a um conjunto de regras em forma de artigos, parecida com as leis, com orientações, proibições, obrigações, competências, infrações e multas direcionadas para normatizar o município e agir nos usos e costumes da população (SENA, 2017).

Nos dois Códigos de Posturas que existiram na Corumbá do período imperial (1875 e 1883), é possível identificar o amplo leque de atuação da Câmara Municipal, com variados assuntos relacionados aos espaços, aos corpos e às atividades: Saúde pública, Venda de gêneros, Concessões, Medições e alinhamentos, Limpeza, Obras públicas, Segurança pública, Açougues, Matadouros, Cemitérios, Reunião de pessoas/festas, Roças/cercamento, Venda e fabricação de pólvora e explosivos, Criação e Circulação de animais, Casa de negócio, Oficinas, Tabernas, Extração de lenha e madeira, Envenenamento de couro, etc. Este conjunto de assuntos, disposto na forma de lei, contemplava uma parte expressiva dos problemas referentes a organização e funcionamento do município.

A reformulação das posturas ou a adição de artigos complementares ocorreram quando novas situações surgiam. Os vereadores, os empregados da Câmara ou outras autoridades propunham a inclusão de itens referentes 
a práticas que deveriam ser regulamentadas e fiscalizadas. Isso ocorria porque as posturas davam respaldo à vistoria e à interferência realizada pelos empregados da municipalidade, e serviam como norteadora para que outros indivíduos cobrassem da Câmara fiscalização, punição e melhorias relacionadas ao espaço urbano. As posturas eram mecanismos do exercício de poder da Câmara Municipal, e seus artigos propunham organizar o espaço e disciplinar as populações em prol do "progresso" e da "civilização" que as elites de Corumbá tanto almejavam e que condiziam com os princípios da "modernidade" vigentes no momento (SENA, 2017).

Com as posturas e outros dispositivos (editais, proibições, advertências, multas, inspeções etc.), a Câmara procurava promover a modernidade e a urbanidade, com introdução de hábitos de civilidade à moda europeia e já presentes entre as elites das maiores cidades do país. Sua interferência no município se deu a partir de uma mentalidade da época, com tentativas de colocar práticas e costumes que confrontavam aos das populações, principalmente as mais baixas. Existia a preocupação com a salubridade, o embelezamento, o ordenamento, a circulação e a boa ordem do espaço urbano, daí o combate a hábitos tidos como não requintados em nome dos "bons costumes" e do "progresso". Dentre os hábitos indesejáveis pelos legisladores estavam o consumo excessivo de aguardentes, os jogos proibidos, os ajuntamentos, batuques com cantorias, a movimentação de pessoas consideradas loucas, a comercialização irregular, o abate de animais em residências e a circulação destes em vias públicas e a exposição de lixos e materiais em decomposição.

O primeiro Código de Posturas da municipalidade corumbaense foi aprovado em 1875 pela Assembleia Legislativa provincial. Diante de outros assuntos relacionados ao município, essa legislação deu especial atenção à higiene pública, que apareceu contemplada no primeiro título, inaugurando as orientações sobre o espaço urbano e evidenciando que as autoridades municipais estavam preocupadas com o tema e empenhadas em reverter o quadro sanitário presente nos anos iniciais após a Guerra.

Os habitantes da vila, a partir de então, estavam obrigados a levar ao Paço da Câmara, nos dias $1^{\circ}$ e 15 de cada mês, seus filhos, curatelados, tutelados, escravos e mais pessoas que lhes fossem subordinadas para serem vacinadas contra a Varíola, caso ainda não tinham sido. Quem assim deixasse de fazer, tornava-se infrator e deveria pagar multa de $10 \$ 000$ réis ou ficaria preso por quatro dias, além de ser compelido a fazer vacinar seu dependente (MATO GROSSO, 1875). 
Como região formada por propriedades rurais devotadas à criação bovina, o abate de gado e o envenenamento (curtimento) de couro estiveram entre as preocupações da municipalidade. A matança de gado ficou proibida no perímetro da vila, nos seus arrabaldes próximos ou locais onde com facilidade o ar infectado pudesse causar danos à saúde pública. As penalidades ficaram em $5 \$ 000$ réis de multa ou dois dias de prisão (SENA; NOGUEIRA, 2015).

O envenenamento de couro, que era um dos itens principais de exportação provincial, também ficou proibido na área da vila ou em locais que pudesse provocar algum problema à saúde. A penalidade para esse tipo de infração foi maior, com multa de $30 \$ 000$ ou de 10 dias de prisão. Além disso, os açougues seriam fiscalizados uma vez por semana, para evitar irregularidades ou alterações sanitárias no comércio de carnes. O objetivo era barrar qualquer atividade envolvendo o abate de animais e o curtimento de couros na área urbana que se configurava, acabando assim com práticas até então frequentes.

A alimentação deveria ser comercializada conforme os padrões higiênicos do momento. Além da carne, ficou proibida a venda de gêneros corrompidos, falsificados ou alterados, com pena de $25 \$ 000$ ou 8 dias de prisão, além das penalidades judiciais que correspondiam a esses atos.

Os espaços públicos também precisavam estar sadios, por isso ficou proibida a instalação de latrinas com despejo para as ruas ou lugares de uso comum. Para o caso de latrinas já instaladas antes da promulgação das Posturas, os proprietários ficaram obrigados de fechá-las dentro de 15 dias, depois de intimados pelo fiscal da Câmara. Os infratores, além de mandar executar o serviço, seriam punidos com 8 dias de prisão. A presença de lama ou água estagnada, que pudessem exalar miasmas à saúde pública também estava na mira das autoridades municipais, que igualmente proibiu o trânsito desordenado de animais suínos, caprinos e caninos e outros no perímetro urbano. A população também ficou proibida de "fazer estrumeira", jogar lixo, animais mortos ou moribundos nas ruas e praças.

Os impedimentos e orientações foram reforçados nas posturas implantadas em 1883. As novas posturas aumentaram o valor das multas e dos dias de prisão para os que descumprissem a proibição da matança de gado e do envenenamento de couro na zona urbana; e, para os que não providenciassem a limpeza das casas e das vias públicas, o controle de animais e a vacinação. $O$ aumento das multas é uma nítida demonstração da permanência de práticas proibidas pela municipalidade nas primeiras posturas. A própria aprovação de um novo Código foi motivada pela necessidade de cobrir falhas 
do regulamento anterior, e visava abarcar outros setores e práticas que precisavam ser normatizados pela municipalidade (SENA, 2017).

Foi assim que o cemitério e as formas de enterramento foram contemplados. O cemitério público foi construído com orçamento municipal, sendo área de jurisdição da Câmara, responsável pela contratação e pagamento dos empregados nomeados para o serviço. Enquanto a Câmara não tivesse um regulamento especial para o serviço do cemitério, algumas normas sobre os enterramentos foram asseguradas no Código de 1883. Assim, nenhum cadáver seria conduzido ao cemitério, sem ter um esquife ou caixão fechado, estando os infratores sujeitos à multa de $20 \$ 000$ réis ou 6 dias de prisão. A sepultura não poderia ter menos de seis palmos abaixo da superfície da terra, e nem deveria enterrar mais de um cadáver por cova. As exumações ocorreriam depois de cinco anos de enterramento do corpo, exceto por requerimento judicial ou policial. Além disso, as covas e catacumbas de exumações não poderiam ficar abertas por mais de 24 horas (MATO GROSSO, 1883).

Os cemitérios foram alvos de autoridades e sanitaristas do oitocentos. Apontados como locais propícios para a produção de miasmas e o surgimento de doenças, os cemitérios passaram a serem os principais espaços para o sepultamento de mortos e não mais as igrejas, onde muitos restos mortais foram retirados (REIS, 2004). Os cemitérios deveriam ficar distantes do perímetro urbano e serem dotados de cuidados sanitários. Em Corumbá, a municipalidade buscou interferir nas formas como eram realizados os sepultamentos, fixando normas e punições para os infratores.

O estudo comparativo das Posturas Municipais de Corumbá aprovadas em 1875 e em 1883 nos permite constatar um crescimento na preocupação da municipalidade com a higiene pública. Este crescimento, apesar de ser produto de ações locais, não pode ser dissociado do processo de racionalização do espaço urbano e normatização do comportamento social que estava em curso no decorrer do Império. Neste sentido, quando afirmamos que as Posturas Municipais da Corumbá Imperial pretendiam coibir condutas da população que prejudicavam o asseio e a salubridade pública, não estamos afirmando que o comportamento dos vereadores de Corumbá era uma exceção no contexto do Império. Pelo contrário, as pesquisas de autores como, Silveira (2007), Ávila (2010), Aguiar (2011), Souza (2012), Rossi e Weber (2015), dentre outros, nos permite afirmar que a experiência de gestão do espaço urbano que estava sendo implantando em Corumbá nos decênios de 1870 e 1880 apresenta semelhanças com experiências que ocorriam em outras localidades do Império. 
Inserida num contexto marcado pela valorização do saber médico, os Códigos de Posturas da Corumbá Imperial apontavam para a necessidade de uma imposição da higiene e, consequentemente, concediam uma atenção especial para a fiscalização das práticas sociais que comprometiam a salubridade urbana. Dentro daquele contexto, a documentação produzida pela Câmara de Corumbá oferece importantes elementos para uma reflexão sobre a distância entre a cidade higiênica - desejada pela municipalidade e prescrita nas Posturas Municipais - e a cidade insalubre que ganhava forma no cotidiano da população corumbaense.

\section{A higiene pública entre as leis e as práticas sociais: o caso de Corumbá}

Na seção anterior do texto destacamos o uso das Posturas Municipais para assegurar e promover hábitos de higiene na população de Corumbá. No entanto, a simples existência de uma lei não garante a adesão espontânea da sociedade às determinações fixadas pelo texto jurídico. E, como demonstrou Thompson (1987), em sua clássica obra, Senhores e Caçadores, ${ }^{3}$ a lei precisa ser interpretada como um "campo de conflito" no qual atuam grupos sociais com prioridades e valores culturais distintos.

No caso específico do nosso estudo as Posturas Municipais de Corumbá instituíam multas para o cidadão que colocasse em risco a salubridade urbana e a própria existência da multa era um indicativo de que os legisladores previam a resistência da sociedade local. Por limitações impostas pelas fontes documentais, não foi possível saber se as multas previstas nas Posturas foram aplicadas com frequência. No entanto, localizamos documentos redigidos pela Câmara Municipal que nos permitem inferir que havia uma distância entre as normas de higiene fixadas pela municipalidade e o cotidiano social.

O primeiro documento data de 1877. Trata-se de um Ofício encaminhado para a Câmara pelo Fiscal Emilio Ponsolle, que foi um dos primeiros fiscais incumbidos de zelar pelo cumprimento das Posturas aprovadas pela municipalidade corumbaense em 1875. Diante da sua incumbência, Ponsolle deparou-se com uma situação difícil: a resistência da população em atender as determinações previstas no Código de Posturas. No seu Relatório direcionado aos vereadores, o Fiscal afirma que:

\footnotetext{
${ }^{3}$ Nessa obra, Thompson buscou em fontes legislativas elementos para compreender os "valores culturais dos caçadores". Ele concluiu que o ponto central do "conflito" foi a tensão gerada pela consolidação da "propriedade privada" e pelo uso da lei para proibir uma prática social consideradas justas e legítimas pelos caçadores.
} 
Por falta de imposição de penas àquelas pessoas que deixam de proceder a limpeza das suas c3asas e seus quintais, pouco tenho conseguido, por isso que raras são aquelas que tem acedido as minhas intimações a respeito (Relatório do Fiscal Emilio Ponsolle enviado à Câmara Municipal, 26/12/1877).

As palavras do Fiscal da Câmara citadas acima registram a dissonância que havia entre a intenção da municipalidade e o comportamento da sociedade corumbaense. E, na opinião deste Fiscal, a situação era agravada pelas deficiências do próprio Código de Posturas. Em uma determinada passagem do seu Relatório, Ponsolle afirma que: "Tenho enviado todos os esforços possíveis para a que não seja letra morta, a providência consignada no Código de Posturas, mas tão defeituoso é ele, que oferece tantos obstáculos de modo a não poder alcançar a felicidade dos vossos munícipes" (Relatório do Fiscal Emilio Ponsolle enviado à Câmara Municipal, 26/12/1877).

Em 1881 o Fiscal da Câmara de Corumbá, Gregório Henrique do Amarante, escreveu um Relatório informando suas ações em prol da salubridade urbana. Neste, o Fiscal informou estar usando um "sentenciado" fornecido pelo Delegado de Polícia para roçar a "maior parte das ruas e praças desta cidade e povoação do Ladário" e recomendou que a Câmara mandasse limpar a estrada que ligava Corumbá até Ladário. Na opinião do Fiscal, a limpeza da estrada era necessária para "o bem da saúde pública" e também era um serviço que a população merecia, "vista da contribuição que os mesmos habitantes pagam anualmente a esta Câmara" (Relatório do Fiscal Gregório Henrique do Amarante à Câmara, 18/4/1881). O mesmo relatório contém um interessante registro de fiscalização de açougues. O Fiscal informa dois açougues que foram multados e descreve com detalhes um dos casos de infração que ele multou. Vejamos o que diz o documento sobre a infração das Posturas praticada pelo cidadão André de Luchi nas palavras do próprio Fiscal:

O açougueiro André de Luchi, além de já ter vendido carne em estado de putrefação pelo que foi multado, ocorre mais, que no dia 15 do corrente (Sexta-Feira da paixão do nosso Redentor), conduziu para o seu açougue, segundo fui informado por João Galache, uma rês morta de peste; por isso dirigi-me ao mencionado açougue coadjuvado pela polícia, onde encontrei já exposta a venda a dita rês, que pelo péssimo estado da magreza e diferentes manchas pretas que tinha a carne, mandei que fosse imediatamente enterrada, o que se efetuou na minha presença, deixei de multá-lo por não ter ainda vendido a dita carne. 
Esta ocorrência assaz de importância chama a atenção de Vs. Senhorias, a bem da saúde pública (Relatório do Fiscal Gregório Henrique do Amarante à Câmara, 18/4/1881).

As infrações cometidas pelo açougueiro André de Luchi corroboram a ideia de que a simples existência das Posturas não assegurava à municipalidade de Corumbá o controle sobre o comportamento da sociedade local. Assim, concordamos com Imízcoz (2004, p. 121) quando este afirma que: "Las normas no son la causa mecánica de la conducta sino efectos de la situación relacional de la que forman parte los individuos".

Interpretando as normas e leis como produtos de situações relacionais, podemos ampliar nossa percepção sobre os problemas de higiene pública registrados na documentação da Câmara Municipal de Corumbá. Um destes problemas diz respeito à proliferação de cães de rua e ao risco que eles representavam para a salubridade da população local. Para atacar este problema, o Fiscal Amarante adotou uma atitude radical e violenta: a distribuição de "bolas" com veneno. Aqui estamos diante de uma prática não prevista nas Posturas - o extermínio de cães de rua, contudo, esta prática atendia ao interesse da municipalidade que era reduzir os riscos de doenças.

Apesar de reprovável para os padrões contemporâneos, o extermínio de cães de rua por envenenamento era uma atitude preventiva comum no Brasil imperial e visava prevenir a transmissão da raiva. Outro tipo de atitude preventiva registrada pelo Fiscal Amarante foi a proibição da "lavagem de roupas no porto desta cidade, onde os carretões condutores de água para o consumo da mesma enchem suas pipas [...]" (Relatório do Fiscal Gregório Henrique do Amarante à Câmara, 18/4/1881).

$O$ problema relacionado à água continuou nos anos seguintes. Em ofício à municipalidade em 1887, o Delegado de Higiene e da Saúde do Porto, Dr. Manoel Joaquim dos Santos, ressaltou que era

de grande utilidade para a saúde pública haver um lugar no porto desta cidade, destinado exclusivamente para extração d'água e não sendo acessível aos carros de condução o ponto, que melhor se presta a esse fim, consulto a V. S. sobre a possibilidade de fazer-se uma rampa ou coisa equivalente, que sirva em qualquer época do ano, para o mencionado serviço, obrigando-se deste modo o grave inconveniente de usar a população de água impura pelas matérias lançadas das embarcações fundeadas (Ofício do Dr. Manoel Joaquim dos Santos, Delegado de Saúde do Porto, à Câmara Municipal, 18/11/1887). 
Tanto na Europa, quanto na América, o problema do consumo de águas poluídas ganhou importância na segunda metade do século XIX, sobretudo depois da divulgação da teoria da transmissão hídrica do Cólera, apresentada pelo médico inglês Jonh Snow, em 1854 (SNOW, 1999). Sob a influência desta nova teoria, a preocupação com a qualidade das águas foi intensificada. ${ }^{4}$

Na cidade de Corumbá, a preocupação com a qualidade das águas captadas no rio Paraguai e comercializadas em pipas esteve presente nas décadas finais do século XIX e também nas primeiras décadas da República. O fato demonstra a persistência de um problema de salubridade urbana que a municipalidade conhecia, mas não conseguia solucionar. Feita essa pequena digressão, convém voltarmos o foco para a análise dos relatórios de fiscais da Câmara de Corumbá produzidos no período imperial.

O terceiro relatório localizado na nossa pesquisa data de 1887 e foi redigido pelo Fiscal Adão da Cunha Kenippel. Esse cidadão já tinha ocupado interinamente o cargo de fiscal em outubro e novembro do ano anterior, e a partir de 1887 ele foi efetivado no cargo e exerceu sua função por mais tempo tendo como base o Código de Posturas de 1883. Isto significa dizer que ele fiscalizou as condições de higiene da cidade usando um dispositivo jurídico mais elaborado do que o implantado em 1875.

O relatório do Fiscal Kenippel apresenta uma estrutura textual mais desenvolvida. Deste documento, destacamos o subtítulo "Salubridade Pública", do qual procede a seguinte citação:

É de indeclinável conveniência de obrigar-se aos proprietários de muitos cortiços existentes nas principais ruas desta cidade a fazerem latrinas, medida que muito concorrerá não só para o asseio da cidade como também para melhorar o estado sanitário dela (Relatório do Fiscal Adão da Cunha Kenippel à Câmara Municipal, 17/1/1887).

A preocupação de Kenippel com as latrinas evidencia a intensificação desse problema para a salubridade urbana. Com o crescimento da população, cresceu também o volume de matérias fecais produzido e o descarte destas matérias muitas vezes era feito em vias públicas ou em barrancas.

\footnotetext{
${ }^{4}$ A respeito do crescimento da preocupação com a qualidade das águas consumidas por populações humanas ocorrido na segunda metade do século XIX, Sant'Anna afirma que: “As pesquisas epidemiológicas de Jonh Snow mostravam que haveria um risco importante do contato dos seres humanos com as águas poluídas, suspeitas de provocar o cólera: essa doença não seria ocasionada simplesmente por qualquer sujeira, mas sim pela contaminação da água com excremento. Era o começo de um novo olhar sobre as águas e sobre as doenças contagiosas" (SANT'ANNA, 2007, p. 215).
} 
Outra autoridade responsável pela higiene do município também deu ênfase ao problema do descarte das latrinas com matérias fecais. O médico e Delegado de Higiene e da Saúde do Porto, José Marques da Silva Bastos, oficiou à Câmara sobre a necessidade de o Fiscal "recomendar aos habitantes desta cidade limpeza nos quintais, e desinfecções de suas casas e latrinas, bem como remoção do lixo, que ainda se encontra em algumas ruas e praças" (Ofício do Dr. José Marques da Silva Bastos, Delegado de Higiene, à Câmara Municipal, $11 / 2 / 1887)$. Bastos voltou a fazer nos meses seguintes essas recomendações, demonstrando sua preocupação com o estado sanitário de Corumbá (Ofício do Dr. José Marques da Silva Bastos, Delegado de Higiene, à Câmara Municipal, 27/6/1887).

Certamente o problema das latrinas não era novo. No entanto, o conteúdo do relatório do Fiscal Kenippel e dos ofícios do Delegado de Higiene não pode ser dissociado da epidemia de Cólera que atingiu Corumbá nos meses finais de 1886 e nos primeiros meses de 1887.

\section{Insalubridade urbana e a epidemia de Cólera}

Em dezembro de 1886, a população de Corumbá defrontou-se com os primeiros óbitos provocados pelo Cólera que chegou à cidade pelo porto fluvial. Nos meses de janeiro e fevereiro do ano seguinte, configurou-se uma situação de epidemia que provocou alterações no comportamento da sociedade corumbaense. Reagindo ao impacto da epidemia, a Câmara Municipal e outras instituições passaram a fiscalizar e empreender medidas mais enérgicas no controle da doença e na higienização urbana.

Com base nos documentos localizados no acervo da Câmara Municipal de Corumbá, sabemos que durante a epidemia de 1886/1887 ocorreram casos de abandono de enfermos e de cadáveres nas ruas da cidade (Ofício do VicePresidente da Câmara Luis Augusto Esteves ao Delegado de Polícia Joaquim Amaro Fernandes, 8/12/1886; Ofício do Dr. Manoel Joaquim dos Santos à Câmara Municipal, 8/12/1886). E, sabemos também, que a municipalidade aconselhou a realização de limpeza nas casas, latrinas e espaços públicos, nomeou um fiscal adjunto para aumentar a fiscalização, promoveu visitas domiciliares para verificar o estado sanitário, ordenou a matança de porcos que circulavam pelas ruas e o seu despejo no rio abaixo da área portuária, intensificou a fiscalização dos açougues e casas de comércio, distribuiu medicamentos, providenciou um lazareto para internação dos coléricos e interferiu nos hábitos de sepultamento da população local. 
O presidente da Câmara em exercício no momento da epidemia, Tenente Coronel Antonio Antunes Galvão, narrou detalhes do comportamento da população nos dias em que a doença atingiu suas primeiras vítimas.

[...] Tendo aparecido aqui a 5 do corrente [dezembro de 1886] alguns casos de Cólera Morbus e causando isso um grande pânico de muitas famílias correram de suas casas abandonando a cidade em procura de abrigo a tão terrível epidemia e prevendo nessas retiradas maiores calamidades procurei persuadir a muitos do quanto era funesta essa medida e fiz publicar mesmo a 7 do corrente um boletim [...], aconselhando limpeza e fumigações como os melhores preservativos de tal enfermidade pois com tais providências pouco ou nada se devia temer. Vendo porém que por meios persuasivos nada consigna mesmo porque muitos se haviam já retirado, deixando imundícias em seus quintais, e conhecendo a urgente necessidade de fazer-se uma visita de todos os focos de infecção que encontrasse e que tendessem a agravar as nossas condições [...] (Ofício do Presidente da Câmara Municipal em exercício, Antonio Antunes Galvão, à Presidência da Província, 17/12/1886).

Uma parte dos trabalhos realizados pela municipalidade durante o enfrentamento da epidemia de Cólera foi registrada em outro documento elaborado por Antonio Antunes Galvão - o Relatório encaminhado para a Câmara Municipal no dia 17 de fevereiro de 1887. Nesse documento, Galvão apresenta informações sobre o "hospital" improvisado pelo poder público para atender os enfermos. Segundo Galvão,

O hospital foi criado unicamente para os que não tinham meios ou eram abandonados, conforme se vê dos ofícios relativos a sua criação. [...]. Baixaram ao hospital, durante a epidemia, quarenta e tantos doentes, dos quais morreram mais da metade (27) porque a maior parte deles eram recolhidos em estado já muito desesperador (Relatório do ex-vereador Tenente Coronel Antonio Antunes Galvão ao Presidente da Câmara José Joaquim Rabello informando sobre o Cólera, 17/2/1887).

O testemunho que o Tenente Coronel nos deixou sobre a epidemia é interessante porque registra reações provocadas pelo Cólera na sociedade corumbaense. Para Galvão, a doença teria atingindo cerca de 1.000 pessoas - um número expressivo para uma população que na época não chegava a 9 mil habitantes. 
No momento em que Galvão passou a direção da Câmara aos vereadores eleitos para o quadriênio que iniciou em janeiro de 1887, ele apresentou um Relatório descrevendo outras informações a respeito da epidemia (Relatório de Antonio Antunes Galvão, ex-Presidente da Câmara, apresentado aos novos vereadores do quadriênio 1887-1890, 7/1/1887). Na sua avaliação, o Cólera ingressou por embarcações que trouxeram passageiros com a enfermidade, ganhando vulto na cidade diante do desasseio que ela vivenciava. Aspectos como o número excessivo de currais nas residências, de cães e porcos nas ruas, como frisado anteriormente, e a existência "cloacas construídas sem observar as mais comezinhas leis da higiene", ganharam destaque na sua avaliação sobre o agravo da epidemia. Esses, atrelado a outros problemas, como a permanência do abate de animais em quintais e o curtume de couro no perímetro urbano, como era proibido desde o primeiro Código de Postura do município, estiveram entre os fatores que contribuíram para o aumento do número de vítimas. Galvão destacou ainda que

Ninguém ignora que o abandono foi o elemento mais destruidor que surgiu nos calamitosos dias do Cólera. Quando se recebia um aviso ou se tinha conhecimento de que existia um enfermo, precisando dos socorros do lazareto, nem sempre se podia com presteza fazê-lo transportar por não haver quem quisesse sujeitar-se a esse serviço mesmo por bom preço; e muitas vezes teve-se necessidade de fazer escoltar pessoal para isso (Relatório de Antonio Antunes Galvão, ex-Presidente da Câmara, apresentado aos novos vereadores do quadriênio 1887-1890, 7/1/1887).

A epidemia de Cólera parece ter encontrado um ambiente favorável na área urbana de Corumbá, porque nela havia situações e práticas insalubres que fragilizam a saúde da população. A municipalidade, desde os seus primeiros anos de existência, tentou criar novas formas de comportamento e introduziu leis que visavam reprimir determinados hábitos não condizentes com as características citadinas que a localidade vivenciava. O número reduzido de empregados municipais colaborava para que as leis fossem burladas, e, consequentemente, facilitava a continuidade de hábitos proibidos pelas Posturas em vigor na época.

Considerando os documentos consultados sobre a epidemia de Cólera do biênio 1886/1887, constatamos que havia uma distância entre a lei e as práticas de higiene da população local. Conforme o ex-vereador Antonio Galvão, parte do que a cidade vivenciou durante a epidemia foi consequência de um "descostume em obedecer a lei" (Relatório de Antonio Antunes Galvão, 
ex-Presidente da Câmara, apresentado aos novos vereadores do quadriênio 1887-1890, 7/1/1887).

\section{Considerações Finais}

No período em que escrevíamos este texto, mais precisamente no dia 23 de setembro de 2019, o telejornal local (de Corumbá) apresentou uma reportagem sobre o Dia Mundial da Limpeza (21 de setembro) e noticiou a ocorrência de ações pró limpeza de espaços públicos em diversos países e cidades. Em Corumbá, o Dia Mundial da Limpeza resultou em ações promovidas no dia 22 de setembro. Segundo a matéria, o ponto de encontro foi a Praça do Ecoparque da Cacimba, onde dezenas de voluntários, entre jovens, adultos e crianças, participaram com o objetivo de retirar o lixo que se encontrava no local. 0 Ecoparque da Cacimba deveria ser uma área de conscientização ambiental, no entanto, a frequente presença de lixo no local indica a existência de um distanciamento entre o destino planejado pelo poder público para a área e o seu efetivo uso social. ${ }^{5}$

Os voluntários retiraram uma quantidade expressiva de lixo. 0 material inclua partes de mobiliários e de bicicletas, garrafas plásticas, pneus, portas, etc. Ação semelhante ocorreu no município de Ladário, na região do porto. Na mesma edição do jornal, foi reportado que a prainha do Porto Geral de Corumbá amanheceu na segunda-feira (23/9/2019) repleta de lixo deixado pelos frequentadores que usam a área para o lazer no fim de semana. É preocupante porque esses e os lixos retirados pelos voluntários estavam às margens do rio Paraguai, que abastece de água as duas cidades brasileiras e as bolivianas vizinhas (Puerto Suárez e Puerto Quijarro). Além de ser essencial para o abastecimento das populações residentes na fronteira Brasil/Bolívia, o rio Paraguai é o principal curso hídrico do bioma Pantanal e a qualidade das suas águas influencia na fauna e na flora da região.

Felizmente, não identificamos notícias de ocorrência de Cólera em Corumbá neste início do século XXI, mas sabemos que o lixo jogado em terrenos baldios, nas margens do rio e outros espaços provocam a proliferação de insetos e ratos, amplia o risco de doenças e prejudica o equilíbrio ambiental. Os mosquitos, por exemplo, têm anualmente causado surtos de Dengue, Chikungunya e Zika. Parte destes problemas ocorre porque uma parcela da

\footnotetext{
${ }^{5}$ A matéria "Dezenas de voluntários participam do Dia da Limpeza em Corumbá" pode ser vista também no endereço: http://g1.globo.com/mato-grosso-do-sul/mstv-1edicao/videos/t/corumba/v/ dezenas-de-voluntarios-participaram-do-dia-da-limpeza-em-corumba/7945180/
} 
população não cuida de quintais, descarta o lixo em locais inadequados e não segue orientações para a manutenção da limpeza da área urbana. Hoje, temos um grau de conhecimento maior sobre os fatores que provocam o surgimento e a proliferação de doenças e sabemos que os problemas sanitários possuem uma historicidade.

No caso específico de Corumbá, as décadas finais do Império foram marcadas por uma crescente preocupação com as condições sanitárias de sua área urbana e com as práticas de higiene da população local. Naquele contexto, a municipalidade tentou (re)ordenar o espaço urbano, normatizando as práticas de higiene e atacando os focos de insalubridade, conforme frisavam as orientações modernas sobre o tema. Contudo, parte da população residente em Corumbá burlava as normas fixadas nos Códigos de Postura.

No decorrer da pesquisa nas fontes documentais, constatamos a existência de diferenças entre os interesses de autoridades locais e as práticas cotidianas da população. Esta demonstrou-se resistente em aderir às normas de higiene fixadas pela municipalidade; e, a Câmara, por sua vez, tentou coibir, pela força da lei, da fiscalização e da punição, hábitos considerados prejudiciais à salubridade urbana. Argumentos como o reduzido número de empregados da municipalidade, a resistência da população e o baixo orçamento municipal comumente foram utilizados pelos vereadores para justificar o alcance limitado dos Códigos de Posturas. Nestas condições, Corumbá encerrou o período imperial provida de leis e instituições que atuavam na área da higiene pública sem alcançar a eficiência desejada pelas autoridades municipais.

Hoje, depois de 242 anos de sua fundação, Corumbá enfrenta outros tipos de problemas relacionados à higiene pública e à saúde da população. Os problemas mudam, mas persistem divergências de interesses e tensões entre a municipalidade e a sociedade. Diante desta persistência, consideramos pertinente finalizar o artigo com a seguinte interrogação: Por que, tanto em Corumbá quanto em outras cidades do Brasil, no que diz respeito à higiene pública, a relação entre a legislação, a sociedade e os agentes do poder público é marcada por constantes desentendimentos e discordâncias entre as partes envolvidas?

\section{Referências Documentais}

DIRETORIA GERAL DE ESTATÍ́STICA. Recenseamento do Brazil em 1872. Rio de Janeiro: Typ. G. Leuzinger, 1874. Vol. 6. 
DIRETORIA GERAL DE ESTATÍ́STICA. População Recenseada em 31 de dezembro de 1890. Rio de Janeiro: Officina da Estatística, 1898.

Leis e Decretos do Império. 1828. L042. Arquivo Histórico do Rio Grande do Sul (AHRS).

MATO GROSSO. Lei Provincial nº 11 de 3 de julho de 1875. Posturas Municipaes da Villa de Santa Cruz de Corumbá. Arquivo Público de Mato Grosso (APMT). Cuiabá-MT.

MATO GROSSO. Lei Provincial nº67, de 31 de maio de 1883. Posturas da Câmara Municipal da cidade de Santa Cruz de Corumbá. Assembleia Legislativa Provincial. Arquivo Público de Mato Grosso (APMT). Cuiabá-MT.

Ofício do Dr. José Marques da Silva Bastos, Delegado de Higiene, à Câmara Municipal, 11/2/1887. Caixa s/nº. Arquivo da Câmara Municipal de Corumbá (ACMC). Corumbá-MS.

Ofício do Dr. José Marques da Silva Bastos, Delegado de Higiene, à Câmara Municipal, 27/6/1887. Caixa s/noํ. Arquivo da Câmara Municipal de Corumbá (ACMC). Corumbá-MS.

Ofício do Dr. Manoel Joaquim dos Santos à Câmara Municipal, 8/12/1886. Caixa s/nº. Arquivo da Câmara Municipal de Corumbá (ACMC). Corumbá-MS.

Ofício do Dr. Manoel Joaquim dos Santos, Delegado de Saúde do Porto, à Câmara Municipal, 18/11/1887. Caixa s/nº. Arquivo da Câmara Municipal de Corumbá (ACMC). Corumbá-MS.

Ofício do Presidente da Câmara Municipal em exercício, Antonio Antunes Galvão, à Presidência da Província, 17/12/1886. Caixa s/nº. Arquivo da Câmara Municipal de Corumbá (ACMC). Corumbá-MS.

Ofício do Vice-Presidente da Câmara Luis Augusto Esteves ao Delegado de Polícia Joaquim Amaro Fernandes, 8/12/1886. Caixa s/no. Arquivo da Câmara Municipal de Corumbá (ACMC). Corumbá-MS.

Relatório de Antonio Antunes Galvão, ex-Presidente da Câmara, apresentado aos novos vereadores do quadriênio 1887-1890, 7/1/1887. Caixa s/nº. Arquivo da Câmara Municipal de Corumbá (ACMC). Corumbá-MS.

Relatório do ex-vereador Tenente Coronel Antonio Antunes Galvão ao Presidente da Câmara José Joaquim Rabello informando sobre o Cólera, 17/2/1887. Caixa s/no. Arquivo da Câmara Municipal de Corumbá (ACMC). Corumbá-MS. 
Relatório do Fiscal Adão da Cunha Kenippel à Câmara Municipal, 17/1/1887. Caixa s/nº . Arquivo da Câmara Municipal de Corumbá (ACMC). Corumbá-MS.

Relatório do Fiscal Emilio Ponsolle enviado à Câmara Municipal, 26/12/1877. In: officios dirigidos a Camara. Corumbá, 1877. Caixa s/nº. Arquivo da Câmara Municipal de Corumbá (ACMC).

Relatório do Fiscal Gregório Henrique do Amarante à Câmara, 18/4/1881. Caixa s/nº . Arquivo da Câmara Municipal de Corumbá (ACMC). Relatório do Fiscal Gregório Henrique do Amarante à Câmara, 18/4/1881. Caixa s/no. Arquivo da Câmara Municipal de Corumbá (ACMC).

\section{Referências Bibliográficas}

AGUIAR, Patrícia Figueiredo. Conduzindo condutas: a transformação do ambiente urbano de Cuiabá a partir do Código de Postura de 1832. Revista Espacialidades [online], v. 4, n. 3, p. 1-17, 2011.

ÁVILA, Vladimir Ferreira de. Saberes históricos e práticas cotidianas sobre o saneamento: desdobramentos na Porto Alegre do século XIX (1850 - 1900). 2010. Dissertação (Mestrado em História) - Programa de Pós-Graduação em História, Pontifícia Universidade Católica do Rio Grande do Sul, Porto Alegre, 2010.

BICALHO, Maria Fernanda. A cidade e o Império: o Rio de Janeiro no século XVIII. Rio de Janeiro: Civilização Brasileira, 2003.

CAMPOS, Maristela Chicharo. O governo da cidade: elites locais e urbanização em Niterói (1835-1890). 2004. 303 f. Tese (Doutorado em História Social e Urbana). Universidade Federal Fluminense, Niterói.

HOBSBAWM, Eric. A era do capital: 1848-1875. Tradução de Luciano Costa Neto. 3. ed. Rio de Janeiro: Paz e Terra, 1982.

IMÍZCOZ, José Maria. Actores, redes e procesos: de los individuos a las configuraciones sociales. Revista da Faculdade de Letras HISTÓRIA, Porto, III Série, v. 5. p. 115-140, 2004.

PERARO, Maria Adenir. Bastardos do Império: família e sociedade em Mato Grosso no século XIX. São Paulo: Contexto, 2001.

REIS, João José. A Morte é uma Festa: ritos fúnebres e revolta popular no Brasil do século XIX. 4. ed. São Paulo: Companhia das Letras, 2004. 
ROSSI, Daiane Silveira; WEBER, Beatriz Teixeira. Legislação imperial e câmaras municipais: saúde e a higiene (Santa Maria/RS, século XIX). Dimensões, vol. 34, 2015, p. 120-144.

SANT'ANNA, Denise Bernuzzi de. Cidade das águas: usos de rios, córregos, bicas e chafarizes em São Paulo (1822-1901). São Paulo: Editora SENAC, 2007.

SENA, Divino Marcos de; NOGUEIRA, Luiz Gabriel de Souza. Matadouro, açougueiros e municipalidade: disciplina no comércio de "carne verde" em Corumbá (1870-1888). Tempos Históricos, v. 19, p. 332-357, 1º sem. 2015.

SENA, Divino Marcos de. Entre articulações e conveniências na Câmara Municipal de Corumbá: Relações de poder, laços sociais e atuação política no final do Império. 2017. Tese (Doutorado em História). Universidade Federal da Grande Dourados, Dourados-MS, 2017.

SENA, Divino Marcos de. Livres e pobres no Centro da América do Sul: um estudo sobre os camaradas (1808-1850). Dourados: Ed. UFGD, 2013.

SILVEIRA, Janaina Souza. A autoridade municipal na Corte Imperial: enfrentamentos e negociações na regulação do comércio de gêneros (1840-1889). Tese (Doutorado em História). Campinas: Unicamp, 2007.

SNOW, John. Sobre a maneira de transmissão do Cólera. São Paulo/Rio de Janeiro: HUCITEC/Abrasco, 1999.

SOUZA, Williams Andrade. Administração, normatização e civilidade: A Câmara Municipal do Recife e o governo da cidade (1829-1849). 2012. 178 f. Dissertação (Mestrado em História Social da Cultura Regional). Universidade Federal Rural de Pernambuco, Recife-PE, 2012.

THOMPSON, Edward Palmer. Senhores e Caçadores: a origem da lei negra. Rio de Janeiro: Paz e Terra, 1987.

Artigo enviado para publicação em 09/04/2020 Artigo aprovado para publicação em 03/12/2020 